\title{
Radical Cystectomy and Various Forms of Urinary Diversions: A Single Centre Experience of 25 Cases
}

\author{
Manish Gupta ${ }^{1}$, H.L. Gupta ${ }^{2}$, Sandeep Malik ${ }^{3}$, Bhart Khadav ${ }^{4}$, Amrit Pal Singh ${ }^{5}$ \\ ${ }^{1}$ Associate Professor, ${ }^{2}$ Associate Professor, ${ }^{3}$ Resident, ${ }^{4}$ Resident, ${ }^{5}$ Resident, Department of Urology, Mahatma Gandhi \\ Medical College and Hospital, Jaipur, India
}

Corresponding author: H.L. Gupta, Associate Professor, Department of Urology, Mahatma Gandhi Medical College and Hospital, Jaipur, India

DOI: http://dx.doi.org/10.21276/ijcmsr.2019.4.1.10

How to cite this article: Manish Gupta, H.L. Gupta, Sandeep Malik, Bhart Khadav, Amrit Pal Singh. Radical cystectomy and various forms of urinary diversions: a single centre experience of 25 cases. International Journal of Contemporary Medicine Surgery and Radiology. 2019;4(1):A38-A41.

\section{A B S T R A C T}

Introduction: For the urologists, it is a challenging task for assessing the optimal mode of urinary tract reconstruction following radical cystectomy. Virtually every segment of gastro-intestinal tract has been used to create urinary reservoirs or conduits. Hence; we planned the present study to analyse patients undergoing radical cystectomy and various forms of urinary diversions.

Material and methods: The present study included assessment of patients undergoing radical cystectomy and various forms of urinary diversions. A total of 25 male patients were included in the present study. Preoperative assessment was done and radical cystectomy was done in all the patients under the hands of skilled uro-surgeons under general anaesthesia. Urinary diversion was performed using IlealNeobladder, sigmoid neobladder, ileal conduit and ureterosigmoidostomy. Follow-up was done in all the patients and records were maintained.

Results: Mean age of the patients of the present study was 60 years, with ranging from 40 to 75 years. Out of the total 25 procedures, 20 were neobladder reconstructions, 1 was ileal conduit and 4 were ureterosigmoidostomy. Mean operative time in all the patients was 270 minutes (range- 180 minutes to 360 minutes). Mean blood loss during the operative procedure was found to be $780 \mathrm{ml}$ (range $400 \mathrm{ml}$ to $1500 \mathrm{ml}$ ).

Conclusion: Radical cystectomy is an effective procedure with good patient postoperative response.Neobladder formation is the most common and better modality then urinary diversions. Hence; it can be easily and safely carried out in patients with good results.

Keywords: Radical Cystectomy, Urinary Diversion

\section{INTRODUCTION}

For the urologist, it is a challenging task for assessing the optimal mode of urinary tract reconstruction following cystectomy. Virtually every segment of gastro-intestinal tract has been used to create urinary reservoirs or conduits. The first reported urinary diversion following cystectomy into the segment of bowel was by Simon in $1852 .{ }^{1-3}$ With increasing experience, a considerable decrease in the mortality and morbidity has been noticed in patients with invasive carcinomas of bladder. Several advancements in the recent past have attempted to improve surgical morbidity and oncological outcomes in Radical Cystectomy. These include application of minimally invasive surgeries (MIS), namely, laparoscopic and robot-assisted Radical Cystectomy (RARC), extended lymphadenectomy templates, and neoadjuvant and adjuvant chemotherapy.,5

Factors that affect the choice of urinary diversion include patients age, body habitus, manual dexterity, physical and mental status and extent of disease. Since there is no unanimous choice for the best method of urinary diversion, all options should be considered.

Hence; we planned the present study to analyse patients undergoing radical cystectomy and various forms of urinary diversions.

\section{MATERIAL AND METHODS}

The present study was conducted in the department of urology of the Mahatma Gandhi Medical College and Hospital and it included assessment of patients undergoing radical cystectomy and various forms of urinary diversions. A total of 25 patients were included in the present study from January 2016 to December 2018. Detailed clinical history and past medical history of all the patients was obtained. Demographic data of all the patients was collected. Complete physical and medical examination was carried out in all the patients. Complete haematological and biochemical examination was carried out. Urine examination was done in all the patients along with radiological investigations (chest $\mathrm{X}$ ray, ultrasonography of abdomen/pelvis, CECT abdomen and pelvis). Trans urethral biopsy of tumour along with deep musclewas taken in all patients. All the patients had 
muscle invasive carcinoma urinary bladder and were treated with standard radical cysto-prostatectomy and bilateral pelvic lymph node dissection in with reconstruction of the lower urinary tract. Urinary diversion/ reconstruction was performed using Ileal Neobladder, sigmoid neobladder, ileal conduit and ureterosigmoidostomy. Follow-up was done in all the patients and records were maintained.

\section{Surgical Intervention}

All the patients were operated upon under general anaesthesia. A standard lower midline abdominal incision was made in all patients. Visceral metastasis was ruled out at the beginning of the laparotomy. Radical cysto-prostatectomy with bilateral pelvic lymphadenectomy was done in male patients which includes the removal of bladder and prostate with its surrounding fat and peritoneal attachments, prostate and the seminal vesicles enbloc.

Urinary diversion was performed using Ileal Neobladder, sigmoid neobladder, ileal conduit and ureterosigmoidostomy. The patient selection criteria for the 3 types of diversions included Patient preference as discussed with each patient pre-operatively, Pre-operative investigations and Intraoperative findings.

Neobladder was performed in patients who had disease confined to the bladder, without urethral or prostate stromal involvement, those without any evidence of extensive pelvic disease, those possessing necessary motor and intellectual skills as how to and when to self catheterize per urethra, and those with normal renal function.

\section{Post Operative Care}

Routine post operative care was followed in all patients with institution of soft diet soon after return of bowel activity.

In the Ileal neobladder and sigmoid neobladder group. Abdominal drain was removed on $7^{\text {th }}$ day. Patients were discharged on $12^{\text {th }}-15^{\text {th }}$ day with the per urethral Foley's catheter and suprapubic catheter. suprapubic cathereter removed on $21^{\text {st }}$ day, DJ stent and foley's catheter were removed on $4^{\text {th }}$ week. After removing the per urethral Foley's catheter, the patients were demonstrated various perineal exercises which aid in voiding and continence.

In the Ileal conduit group, Abdominal drain was removed on $7^{\text {th }}$ day. Patients were discharged on $12^{\text {th }}-15^{\text {th }}$ day after removing the foley's catheter from the conduit and demonstrating the proper application of the urostoma bag and the care of skin surrounding the ostoma site. Ureteral stents were removed on $21^{\text {st }}$ post operative day.

In all the patients, routine post operative investigations such as $\mathrm{CBC}, \mathrm{KFT}, \mathrm{ABG}$ and Serum Electrolytes and serum protein were monitored during the post-operative period in the hospital.

\section{RESULTS}

A total of 25 patients were selected for the study who were operated in the Department of Urology, who had muscle invasive carcinoma urinary bladder. 23 patients had

\begin{tabular}{|l|c|}
\hline Parameter & Value \\
\hline Mean Age (years) & 60 \\
\hline Operative time (minutes) & 270 \\
\hline Blood loss (ml) & 780 \\
\hline Hospital stay (days) & 12 \\
\hline Mortality (number of patients) & 1 \\
\hline \multicolumn{2}{|c|}{ Table-1: Clinical data } \\
\hline
\end{tabular}

\begin{tabular}{|l|c|c|c|c|}
\hline & Ileal neobladder & Sigmoid neobladder & Ileal conduit & ureterosigmoidostomy \\
\hline Performed & $12(48 \%)$ & $8(32 \%)$ & $1(4 \%)$ & $4(16 \%)$ \\
\hline \multicolumn{4}{|c|}{ Table-2: Various types of bladder reconstruction or urinary diversions } \\
\hline
\end{tabular}

\begin{tabular}{|l|c|}
\hline Early complications & Number of patients \\
\hline Paralytic ileus/ electrolyte imbalance & 5 \\
\hline Chest infection & 2 \\
\hline Wound infection & 3 \\
\hline Wound dehiscence & 1 \\
\hline Small bowel obstruction & 1 \\
\hline Urinary leak & 1 \\
\hline Pulmonary embolism & \multicolumn{1}{|c|}{} \\
\hline Mortality (lung complication) & 1 \\
\hline \multicolumn{2}{|c|}{ Table-3: Early complications } \\
\hline
\end{tabular}

\begin{tabular}{|l|c|}
\hline Late complications & Number of patients \\
\hline Urinary retention & 3 \\
\hline Urinary tract sepsis & 1 \\
\hline Incisional hernia & 1 \\
\hline \multicolumn{2}{|c|}{ Table-4: Late complications } \\
\hline
\end{tabular}


transitional cell carcinoma, 2 patients had squamous cell carcinoma (demonstrated histologically on trans-urethral resection biopsies). Patients with squamous cell carcinoma had vesical calculi. Mean age of the patients of the present study was 60 years, with ranging from 40 to 75 years. Mean operative time in all the patients was 270 minutes (range180 minutes to 360 minutes). Mean blood loss during the operative procedure was found to be $780 \mathrm{ml}$ (range $400 \mathrm{ml}$ to $1500 \mathrm{ml}$ ). Mean hospital stay was found to be 12 days, ranging between 10 days to 20 days. Early complications encountered in the present study were Paralytic ileus/ electrolyte imbalance, Chest infection, Wound infection, wound dehiscence, Small bowel obstruction, Urinary leak and pulmonary embolism. Two patients were lost to follow up after attending our Outpatient department for one year. One patient died in theimmediate post operative period from lung complications. Surgical margins were found positive in two patients and required post operative CT/RT. Late complications encountered in the present study were Urinary retention, Urinary tract sepsis and Incisional hernia.

\section{DISCUSSION}

Bladder cancer is the second most common malignancy in the urinary tract and transitional cell carcinoma of the urinary bladder is currently the fourth most common malignancy in men in the Western world. Neoadjuvant chemotherapy, followed by radical cystectomy, extended pelvic lymphadenectomy, and urinary diversion (using an ileal conduit or ileal orthotopic neobladder) is the gold standard therapeutic approach for muscle invasive bladder cancer. However, radical cystectomy comes along with quite a burden for the patient considering a long-term morbidityrate of up to $90 \%$ leading to a considerable mortality rate. ${ }^{8-11}$ In the present study, a total of 25 patients were selected who were operated in the Department of Urology, who had muscle invasive carcinoma urinary bladder and were treated with standard radical cysto-prostatectomy and bilateral pelvic lymph node dissection in males with reconstruction of the lower urinary tract by ilealneobladder, sigmoid neobladder, ileal conduit and ureterosigmoidostomy. Mean age of the patients of the present study was 60 years, with ranging from 40 to 75 years. Out of the total 25 procedures, 20 were neobladder reconstructions, 1 was ileal conduit and 4 were ureterosigmoidostomy. Mean operative time in all the patients was 270 minutes (range- 180 minutes to 360 minutes). Mean blood loss during the operative procedure was found to be $780 \mathrm{ml}$ (range $400 \mathrm{ml}$ to $1500 \mathrm{ml}$ ). Nazim $\mathrm{SM}$ et al determined the medium and long-term outcome of orthotopic continent urinary diversion with ileal (Studer) neo-bladder following radical cystectomy. Thirty eight patients underwent radical cystectomy for invasive bladder tumor with ileal neo-bladder (Studer type) reconstruction. A total of 29 patients (23 males and 6 females) with mean age of $59 \pm 12$ years were included for the final analysis. The mean duration of surgery (both radical cystectomy and urinary diversion) was $520 \pm 70$ minutes. Perioperative complication rate was $24 \%(n=7)$ with surgical site infection in 4 patients, sepsis in 1 patient and 2 had ureteroileal leak. At 6 months follow-up, 22 patients were fully continent while
7 patients had minimal stress / nocturnal incontinence. The continence rate was $93 \%(n=27)$ at one year follow-up. The mean capacity of neo-bladder at 6 months was $384 \pm 66$ mLs. The late complication rate was $17 \%(n=5)$. Three patients developed anastomotic stricture requiring transurethral incision of neo bladder neck, one formed stone in neobladder and one developed incision hernia. All patients had preserved renal functions on follow-up. The survival rate was $80 \%(n=23)$ at a median follow-up of $66.4 \pm 36$ months. Two patients developed local recurrence and four developed distant metastasis. Studer ileal neo-bladder is a safe and effective option for urinary diversion in select patients with good oncological and functional outcomes comparable to contemporary literature, even in a low volume center. ${ }^{12}$

In the present study, mean hospital stay was found to be 12 days, ranging between 11 days to 25 days. Early complications encountered in the present study were Paralytic ileus, Chest infection, Wound infection, wound dehiscence, Small bowel obstruction, Urinary leak and pulmonary embolism. Late complications encountered in the present study were Urinary retention, Urinary tract sepsis and Incisional hernia. SnowLisy et al. analyzed 121 patients of laparoscopic and RARC from 1999 to 2008 at their institute. In their series 17 patients underwent RARC and rest laparoscopic or laparoscopicassisted RC. Median blood loss and operative time were $400 \mathrm{ml}$ and $7.5 \mathrm{~h}$, respectively. Postoperative complications were seen in $43 \%$ of patients, with CD 2 and 3 complications in $24.79 \%$ of all patients. Complications requiring surgical intervention were seen in $11 \%$ of patients. They reported OS of $55 \%$ and recurrence free survival of $71 \%$ at 3 years. ${ }^{13}$

\section{CONCLUSION}

Under the light of above obtained results, the authors conclude that radical cystectomy is an effective procedure with good patient postoperative response. Neobladder formation is the most common and better modality then urinary diversions. Hence; it can be easily and safely carried out in patients with good results.

\section{REFERENCES}

1. Zinman L, Libertino JA. Ileocaecal conduit for temporary and permanent urinary diversion. J Urol. 1975;113(1):317-323.

2. Camey M, Le Duc A. Entero-cystoplastic area cystoprostatectomietotale pour cancer de la vessie. Am Urol. 1979;13(3):114-123.

3. Simon J. Operation for directing the ureteral orifices into the rectum, temporary success, subsequent death, autopsy. Lancet. 1852;2(5):568-570.

4. Gburekh BM, Lieber MM, Blute ML. Comparison of ilealneobladder and ileal conduit urinary diversion with respect to peri-operative outcome and late complications. J Urol. 1998;160(1):721-723.

5. Hautmann RE, Egghart G, Frohneberg D, et al. The Ilealneobladder. J Urol. 1988;139(3):39-42.

6. Hautmann Richard E, Miller Kurt, Steiner Ursula, Wenderoth Ulrich. The ilealneobladder: 6 years experience with more than 200 patients. The Journal of Urology. 1993;150(4):40-45.

7. Momose H, Hirao Y, Tanaka N, Ozono S, Yamada K. 
Complications and quality of life in patients with ileal conduit diversion. Hinyokika Kiyo. 1995;41(11):92735.

8. Gaitonde K, Goyal A, Nagaonkar S, Patil N, Singh DR, Srinivas V, et al. Retrospective review and long-term follow-up of radical cystectomy in a developing country. BJU Int 2002;89Suppl 1:57-61.

9. Bochner BH, Dalbagni G, Sjoberg DD, et al. Comparing open radical cystectomy and robot-assisted laparoscopic radical cystectomy: A randomized clinical trial. EurUrolEur Urol. 2015; 67(6):1042-50.

10. Gupta NP, Kolla SB, Seth A, Dogra PN, Hemal AK, Kumar R, et al. Radical cystectomy for bladder cancer: A single center experience. Indian J Urol 2008;24(5):54-9.

11. Leow JJ, Reese SW, Jiang W, Lipsitz SR, Bellmunt J, Trinh QD, et al. Propensity-matched comparison of morbidity and costs of open and robot-assisted radical cystectomies: A contemporary population-based analysis in the united states. EurUrol 2014;66(2):56976.

12. Nazim SM1, Ather MH1, Abbas F1. Functional and clinical outcome of ileal (Studer) neo-bladder reconstruction: single centre experience from Pakistan.J Coll Physicians Surg Pak. 2014;24(8):586-90.

13. Snow-Lisy DC, Campbell SC, Gill IS, Hernandez AV, Fergany A, Kaouk J, et al. Robotic and laparoscopic radical cystectomy for bladder cancer: Long-term oncologic outcomes. EurUrol 2014;65(1):193-200.

Source of Support: Nil; Conflict of Interest: None

Submitted: 09-01-2019; Accepted: 05-02-2019; Published online: 21-02-2019 